\title{
Albumin-bound paclitaxel and gemcitabine combination therapy in soft tissue sarcoma
}

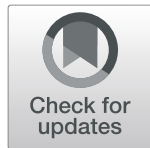

Zhichao Tian ${ }^{1 *} \mathbb{D}$, Fan Zhang ${ }^{1}$, Po Li ${ }^{1}$, Jiaqiang Wang ${ }^{1}$, Jinpo Yang ${ }^{2}$, Peng Zhang ${ }^{1}$, Weitao Yao ${ }^{1}$ and Xin Wang ${ }^{1}$

\begin{abstract}
Background: The evidence that albumin-bound paclitaxel (nab-paclitaxel) is safe and efficacious for the treatment of many types of malignant tumors is continuously increasing. However, the evidence and clinical data of nabpaclitaxel and gemcitabine in metastatic soft tissue sarcoma (STS) treatment are rare.

Methods: The clinical data of metastatic STS patients who received nab-paclitaxel/ gemcitabine chemotherapy between January 2019 and February 2020 were retrospectively analysed. All these patients were treated with nabpaclitaxel/ gemcitabine only after doxorubicin-based chemotherapy had failed. We evaluated the effectiveness and safety of nab-paclitaxel and gemcitabine in these patients.

Results: A total of 17 patients treated with nab-paclitaxel/ gemcitabine were enrolled in this study. One patient with angiosarcoma achieved complete response, 6 patients had partial response, 5 patients achieved stable disease, and 5 patients had progressive disease. The average diameter change in target lesion from baseline was $-19.06 \pm$ 45.74\%. And median progression free survival was 6 months (95\% Cl, 2-9 months). Grade 3 / 4 adverse events were not common, included neutropenia (17.6\%), fatigue (11.8\%), anemia (11.8\%), leukopenia (11.8\%), nausea (5.9\%), peripheral neuropathy (5.9\%), diarrhea (5.9\%), and thrombocytopenia (5.9\%). No treatment-related deaths occurred.

Conclusion: Nab-paclitaxel/ gemcitabine combination chemotherapy is comparatively effective in the treatment of STS, demonstrates low toxicity, and is worthy of further study.
\end{abstract}

Keywords: Albumin-bound paclitaxel, Gemcitabine, Sarcoma, Epithelioid sarcoma, Chemotherapy

\section{Background}

Soft tissue sarcomas (STS) comprise a diverse family of malignancies predominantly of mesodermal origin. Although the incidence of STS is low, there are still more than 40,000 new cases in China each year [1]. After standard treatment is completed, most cases of STS eventually progress into locally unresectable or metastatic advanced STS. The first-line treatment for unresectable or metastatic STS is doxorubicin-based chemotherapy, with an expected overall response rate (ORR) of $11-26 \%$ and a median progression free survival

\footnotetext{
* Correspondence: tianzhichaoyy@163.com

'Department of Bone and Soft Tissue, the Affiliated Cancer Hospital of Zhengzhou University and Henan Cancer Hospital, Zhengzhou 450008, Henan Province, China

Full list of author information is available at the end of the article
}

(median-PFS) of 4-8 months [2, 3]. Docetaxel/ gemcitabine is another common chemotherapy regimen, often considered a second line treatment (after doxorubicin), with an expected ORR and an median-PFS similar to those of doxorubicin $[4,5]$. Multi-target receptor tyrosine kinase inhibitors (TKIs) and programmed cell death protein 1 (PD-1) inhibitors have also been shown to be effective against selective STS, although with a lower ORR and median-PFS than those of doxorubicin and docetaxel/ gemcitabine [6, 7]. Because of the limited ORR and median-PFS obtained with each of the above treatments, the overall survival for advanced STS is approximately only 16 months [8]. Therefore, there is an urgent need for more effective drugs to treat STS.

Albumin bound paclitaxel (nab-paclitaxel) is a new ethanol-free paclitaxel, and was initially developed to

\section{$\triangle B M C$}

(c) The Author(s). 2020 Open Access This article is licensed under a Creative Commons Attribution 4.0 International License, which permits use, sharing, adaptation, distribution and reproduction in any medium or format, as long as you give appropriate credit to the original author(s) and the source, provide a link to the Creative Commons licence, and indicate if changes were made. The images or other third party material in this article are included in the article's Creative Commons licence, unless indicated otherwise in a credit line to the material. If material is not included in the article's Creative Commons licence and your intended use is not permitted by statutory regulation or exceeds the permitted use, you will need to obtain permission directly from the copyright holder. To view a copy of this licence, visit http://creativecommons.org/licenses/by/4.0/ The Creative Commons Public Domain Dedication waiver (http://creativecommons.org/publicdomain/zero/1.0/) applies to the data made available in this article, unless otherwise stated in a credit line to the data. 
overcome toxicities associated with the solvents used in conventional formulations and to potentially improve efficacy [9]. Nab-paclitaxel has been shown to deliver a higher dose of paclitaxel to tumor lesions (compared to solvent-based paclitaxel formulations) and to decrease the incidence of serious toxicities, including severe allergic reactions $[10,11]$. Up to now, nab-paclitaxel has been approved for the treatment of metastatic pancreatic cancer, locally advanced or metastatic non-small cell lung cancer, and metastatic breast cancer [10, 12]. Not only that, there is growing evidence that nab-paclitaxel is effective in the treatment of other malignant tumors [13, 14], including STS [15-17].

Since January 2019, advanced sarcoma patients have been treated in our hospital (a major sarcoma treatment center in central China) with nab-paclitaxel and gemcitabine. In this study, we retrospectively investigate patient outcomes and study the safety and effectiveness of nab-paclitaxel/ gemcitabine combination chemotherapy in STS treatment, with the aim of providing additional evidence to establish clinical study design and to support clinical treatment.

\section{Methods}

Patients and eligibility criteria

All the STS patients in this retrospective study received nab-paclitaxel/ gemcitabine combination chemotherapy between January 2019 and February 2020. This study was approved by the Ethics Committee of The Affiliated Cancer Hospital of Zhengzhou University. All patients provided written informed consent for data collection and research purposes. The inclusion criteria were as follows: 1) histologically proven STS; 2) locally unresectable or multiple metastases; 3) treated with nab-paclitaxel/ gemcitabine chemotherapy; 4) measurable lesions according to the Response Evaluation Criteria in Solid Tumors (RECI $\mathrm{ST}$, version 1.1); 5) The clinical data are complete and can be statistically analyzed.

\section{Treatment protocol}

Patients were administered $300 \mathrm{mg} / \mathrm{m}^{2}$ nab-paclitaxel via intravenous bolus on day 1 , and $1250 \mathrm{mg} / \mathrm{m}^{2}$ gemcitabine via intravenous bolus on days 1 and 8 . All patients received a single sub-cutaneous injection of polyethylene glycol recombinant human granulocyte colony- stimulating factor $100 \mu \mathrm{g} / \mathrm{kg}$ on day 3. The treatment regimen was repeated every 21 days, until manifestation of progressive disease (PD) or unacceptable adverse events (AEs). If grade $3 / 4$ AEs occurred, treatment was delayed until recovery. However, if the delay lasted more than 14 days, the treatment was terminated.

\section{Evaluation of effectiveness and safety}

The baseline characteristics of all STS patients enrolled in this study were reviewed. Treatment effectiveness was evaluated according to the RECIST (version 1.1) criteria every 1 or 2 months using either magnetic resonance imaging or computed tomography. The ORR, disease control rate (DCR), median-PFS and AEs were then evaluated. ORR and DCR were defined based on RECI ST (version 1.1). The National Cancer Institute's Common Terminology Criteria for Adverse Events (version 4.0) was used to evaluated AEs. PFS was defined as the time from initiation of drug treatment to the date of PD or death, and survivors without PD were censored at the last contact.

\section{Statistical analyses}

All data were analyzed using SPSS 21.0 software. The present study comprises a descriptive analysis. Quantitative variables are presented as numerical values (percentage) and medians (range). The corresponding figure was drawn using GraphPad Prism 5.0. PFS was calculated using the Kaplan-Meier method, with a 95\% confidence interval (CI).

\section{Results}

\section{Patient characteristics}

A total of 17 STS patients treated with nab-paclitaxel/ gemcitabine were enrolled in this study. The characteristics of these patients are shown in Table 1 . The cohort included 11 (64.71\%) men and 6 (35.29\%) women. The average patient age was $38.71 \pm 17.35$ years. All patients had stage IV disease. All patients were previously treated with doxorubicin-based or other chemotherapy. The primary tumor site varied significantly. and although primary tumor sites were distributed throughout the body, they were mainly situated in the extremities. There were also markedly differences in histological subtypes. The most common subtype being epithelioid sarcoma $(n=5)$, followed by angiosarcoma $(n=3)$, rhabdomyosarcoma $(n=3)$, undifferentiated pleomorphic sarcoma $(n=2)$, fibrosarcoma $(n=2)$, leiomyosarcoma $(n=1)$, and primitive neuroectodermal tumor $(n=1)$.

\section{Effectiveness of therapy}

Of the 17 patients, 1 patient with angiosarcoma achieved complete response, 6 patients had partial response, 5 patients achieved stable disease (SD), and 5 patients had PD (Fig. 1; Tables 2). The average diameter change from baseline in target lesion was $-19.06 \pm 45.74 \%$ (Fig. 1). The ORR was $41.2 \%$, the DCR was $70.6 \%$, the medianPFS was 6 months (95\% CI, 2-9 months), and the 6months PFS rate was $64.71 \%$ (Table 3; Fig. 1). 
Table 1 Patient demographics and characteristics

\begin{tabular}{|c|c|c|c|c|c|c|c|c|}
\hline Patient No. & ECOG PS & Histological subtype & Stage & Primary site & Metastatic site & Previous DOX chemotherapy & Response & PFS (Months) \\
\hline 1 & 0 & Epithelioid sarcoma & IV & Extremities & Lung and bone & Yes & $P R$ & 6 \\
\hline 2 & 1 & Epithelioid sarcoma & IV & Extremities & Lung and lymph nodes & Yes & PR & 11 \\
\hline 3 & 1 & Epithelioid sarcoma & IV & Extremities & Lung and bone & Yes & PR & 6 \\
\hline 4 & 0 & Epithelioid sarcoma & IV & Extremities & Bone & Yes & SD & 9 \\
\hline 5 & 1 & Epithelioid sarcoma & IV & Extremities & Lung & Yes & PD & 1.5 \\
\hline 6 & 1 & Angiosarcoma & IV & Extremities & Bone & Yes & $C R$ & 12 \\
\hline 7 & 0 & Angiosarcoma & IV & Extremities & Lung & Yes & SD & 8 \\
\hline 8 & 0 & Angiosarcoma & IV & Extremities & Lung & Yes & $P R$ & 7 \\
\hline 9 & 0 & Rhabdomyosarcoma & IV & Head & Lung and Soft tissue & Yes & $P R$ & 9 \\
\hline 10 & 0 & Rhabdomyosarcoma & IV & Trunk & Bone & Yes & SD & 6 \\
\hline 11 & 0 & Rhabdomyosarcoma & IV & Extremities & Lung & Yes & PD & 3 \\
\hline 12 & 1 & UPS & IV & Extremities & Lung & Yes & SD & 6 \\
\hline 13 & 0 & UPS & IV & Pelvis & Lung & Yes & PD & 1.3 \\
\hline 14 & 1 & Fibrosarcoma & IV & Trunk & Lung & Yes & PR & 9 \\
\hline 15 & 0 & Fibrosarcoma & IV & Extremities & Lung & Yes & PD & 1 \\
\hline 16 & 0 & Leiomyosarcoma & IV & Extremities & Lung & Yes & PD & 2 \\
\hline 17 & 1 & PNET & IV & Trunk & Lung & Yes & SD & 3 \\
\hline
\end{tabular}

Abbreviations: ECOG PS Eastern Cooperative Oncology Group performance status, UPS Undifferentiated pleomorphic sarcoma, PNET Primitive neuroectodermal tumor, DOX Doxorubicin-based, PR Partial response, SD Stable disease, PD Progressive disease, $C R$ Complete response. PFS Progression-free survival

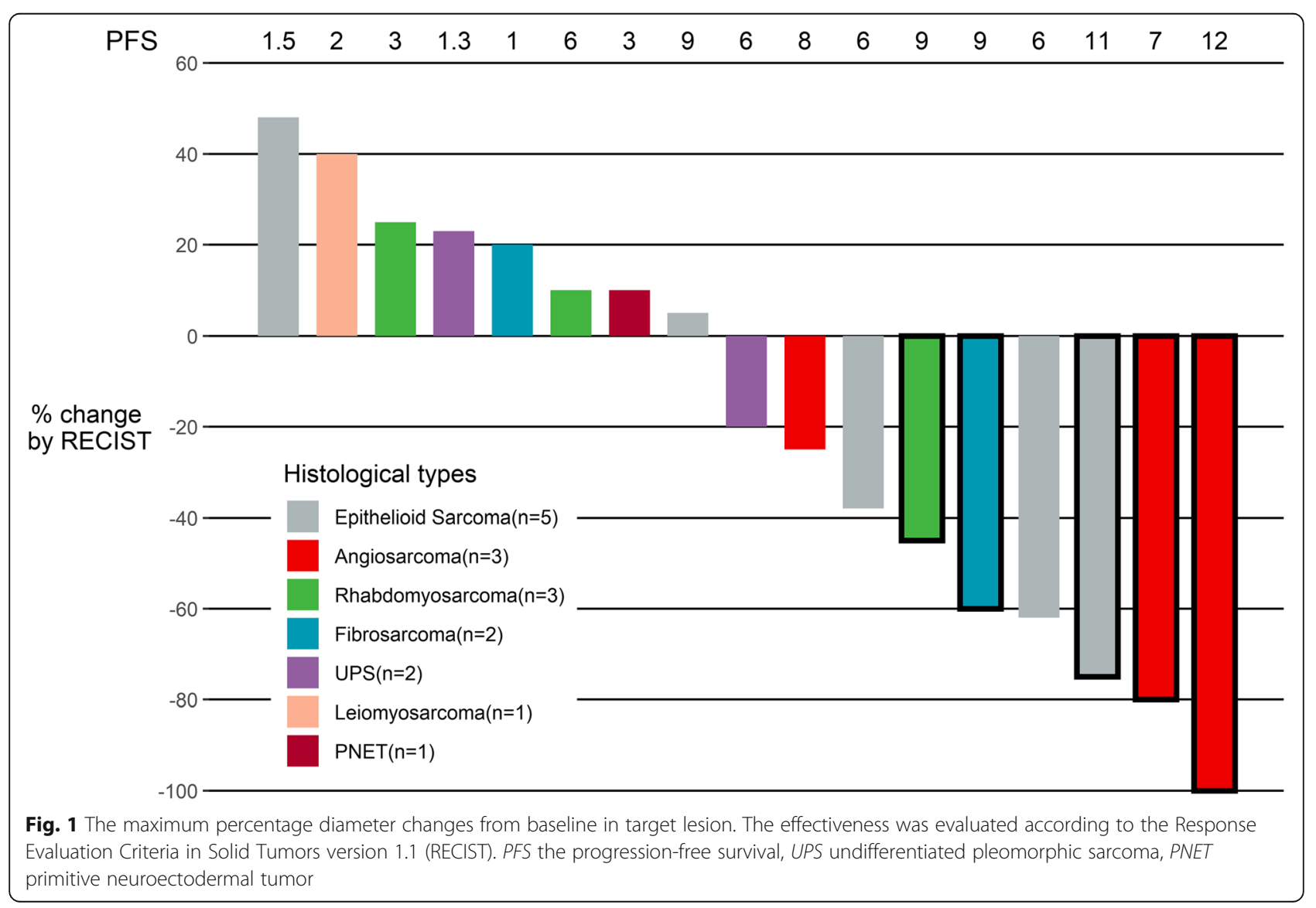


Table 2 Responses of various histological subtypes to treatment

\begin{tabular}{lllll}
\hline Histological subtypes & \multicolumn{4}{l}{ Number of patients } \\
\cline { 2 - 5 } & CR & PR & SD & PD \\
\hline Epithelioid sarcoma $(n=5)$ & 0 & 3 & 1 & 1 \\
Angiosarcoma $(n=3)$ & 1 & 1 & 1 & 0 \\
Rhabdomyosarcoma $(n=3)$ & 0 & 1 & 1 & 1 \\
UPS $(n=2)$ & 0 & 0 & 1 & 1 \\
Fibrosarcoma $(n=2)$ & 0 & 1 & 0 & 1 \\
Leiomyosarcoma & 0 & 0 & 0 & 1 \\
PNET & 0 & 0 & 1 & 0 \\
Total & 1 & 6 & 5 & 5 \\
\hline Abbrations
\end{tabular}

Abbreviations: $C R$ Complete response, $P R$ Partial response, $S D$ Stable disease, $P D$ Progressive disease, UPS Undifferentiated pleomorphic sarcoma, PNET Primitive neuroectodermal tumor

\section{Toxicity and safety}

In general, nab-paclitaxel/ gemcitabine chemotherapy was relatively well tolerated. As shown in Table 4, the most common grade 1or 2 AEs were alopecia (88.2\%, $15 / 17)$, neutropenia $(64.7 \%, 11 / 17)$, fatigue $(52.9 \%, 9 / 17)$, anemia $(47.1 \%, 8 / 17)$, and nausea $(41.2 \%, 7 / 17)$. The grade 3 or 4 AEs were not common, but included neutropenia (17.6\%), fatigue (11.8\%), anemia (11.8\%), leukopenia (11.8\%), nausea (5.9\%), peripheral neuropathy (5.9\%), diarrhea (5.9\%), and thrombocytopenia (5.9\%). No treatment-related deaths occurred.

\section{Discussion}

The taxanes (including paclitaxel and docetaxel) represent a class of chemotherapy drugs that interfere with microtubule function leading to altered mitosis and cellular apoptosis [18]. Paclitaxel is rarely used in the treatment of STS because it demonstrates limited efficacy [19]. The main reason for the limited efficacy of paclitaxel is probably that there is a practical limitation to the delivered dose due to high toxicity [10, 20-22]. The toxicity of docetaxel-based chemotherapy is greater than that of doxorubicin-based chemotherapy. Thus, although the clinical efficacy of the two regimens is similar, docetaxel-based chemotherapy is considered as a second line regimen for the treatment of advanced STS [4].

Table 3 Clinical effectiveness

\begin{tabular}{ll}
\hline Characteristics & Data \\
\hline ORR & $41.20 \%$ \\
DCR & $70.60 \%$ \\
M-PFS (months) & $6(95 \%$ Cl: $2-9)$ \\
6 months PFS rate & $64.71 \%$ \\
\hline
\end{tabular}

Data are presented as percentages or means

Abbreviations: ORR The objective response rate, $D C R$ The disease control rate, $m$-PFS The median progression-free survival
Table 4 Adverse events

\begin{tabular}{lll}
\hline Adverse events & Grade 1-2 & Grade 3-4 \\
\hline Alopecia & $88.2 \%(15 / 17)$ & \\
Neutropenia & $64.7 \%(11 / 17)$ & $17.6 \%(3 / 17)$ \\
Fatigue & $52.9 \%(9 / 17)$ & $11.8 \%(2 / 17)$ \\
Anemia & $47.1 \%(8 / 17)$ & $11.8 \%(2 / 17)$ \\
Nausea & $41.2 \%(7 / 17)$ & $5.9 \%(1 / 17)$ \\
Leukopenia & $35.3 \%(6 / 17)$ & $11.8 \%(2 / 17)$ \\
Peripheral neuropathy & $29.4 \%(5 / 17)$ & $5.9 \%(1 / 17)$ \\
Anorexia & $29.4 \%(5 / 17)$ & \\
Diarrhea & $23.5 \%(4 / 17)$ & $5.9 \%(1 / 17)$ \\
Thrombocytopenia & $23.5 \%(4 / 17)$ & $5.9 \%(1 / 17)$ \\
Alkaline phosphatase increased & $17.6 \%(3 / 17)$ & \\
Fever & $11.8 \%(2 / 17)$ & \\
Abdominal pain & $11.8 \%(2 / 17)$ & \\
Pneumonitis & $5.9 \%(1 / 17)$ & \\
\hline
\end{tabular}

Data are presented as percentages (number events/total)

Treatment with paclitaxel or docetaxel is associated with a number of clinical problems, including poor drug solubility, allergic reactions, serious dose limiting toxicities [18]. These clinical problems are related to the solvents used to dilute these anticancer drugs: Cremophor EL for paclitaxel and polysorbate 80 for docetaxel [22]. To solve these problems, nab-paclitaxel was developed to be free of the conventional solvents used in the injections. The newly nab-paclitaxel is prepared by encapsulating paclitaxel in albumin nanoparticle [9]. The nab-paclitaxel can pass through the leaky capillary junctions in the tumor bed more easily than through the normal vessels in healthy tissue, and is thus taken up selectively by tumor tissues and cells. According to clinical data, nab-paclitaxel offers several improvements over conventional, solvent- and Cremophor-based paclitaxel, including lower toxicities, shorter administration time, higher efficacy, and the lack of a need for premedication [23]. Several previous studies have demonstrated that nab-paclitaxel has greater efficacy and a more favorable safety profile (compared with solvent-based paclitaxel) in many malignancies [13, 24, 25].

To our knowledge, this study is the first to investigate the safety and effectiveness of nab-paclitaxel/ gemcitabine combination chemotherapy in advanced STS patients. In this retrospective observational study, we observed that nab-paclitaxel was effective for the treatment of STS, with an ORR of 41.2\%, and a median-PFS of 6 months. Considering that all of these patients received nab-paclitaxel/ gemcitabine treatment following failed doxorubicin-based chemotherapy, the effectiveness of nab-paclitaxel/ gemcitabine chemotherapy is increased compared to doxorubicin-based chemotherapy and docetaxel/ gemcitabine combination therapy reported by 
Table 5 Clinical trials of nab-paclitaxel in sarcomas currently recruiting

\begin{tabular}{|c|c|c|c|c|c|c|c|}
\hline Title & Phase & Status & Histological subtypes & $\begin{array}{l}\text { Number } \\
\text { of } \\
\text { patients }\end{array}$ & Collaborators & Dates & NCT Number \\
\hline $\begin{array}{l}\text { Nab-paclitaxel and gemcitabine in } \\
\text { advanced STS. }\end{array}$ & $\begin{array}{l}1 \text { and } \\
2\end{array}$ & Recruiting & STS & 45 & $\begin{array}{l}\text { Swiss Group for } \\
\text { Clinical Cancer } \\
\text { Research }\end{array}$ & $\begin{array}{l}\text { Start: October } \\
2018 \\
\text { Completion: } \\
\text { October } 2022\end{array}$ & NCT03524898 \\
\hline $\begin{array}{l}\text { Nab-paclitaxel and gemcitabine for } \\
\text { recurrent/refractory sarcoma. }\end{array}$ & 2 & Recruiting & $\begin{array}{l}\text { Osteosarcoma, Ewing } \\
\text { Sarcoma, } \\
\text { Rhabdomyosarcoma, STS }\end{array}$ & 72 & $\begin{array}{l}\text { H. Lee Moffitt } \\
\text { Cancer Center } \\
\text { and Research } \\
\text { Institute } \\
\text { National Pediatric } \\
\text { Cancer } \\
\text { Foundation }\end{array}$ & $\begin{array}{l}\text { Start: } \\
\text { October } 2016 \\
\text { Completion: } \\
\text { March } 2021\end{array}$ & NCT02945800 \\
\hline $\begin{array}{l}\text { Trial of nab-paclitaxel in patients with } \\
\text { desmoid tumors and multiply relapsed/ } \\
\text { refractory desmoplastic small round cell } \\
\text { tumors and Ewing sarcoma. }\end{array}$ & 2 & Recruiting & $\begin{array}{l}\text { Desmoid tumors, } \\
\text { Desmoplastic small } \\
\text { round cell tumors, } \\
\text { Ewing sarcoma }\end{array}$ & 61 & $\begin{array}{l}\text { Grupo Espanol } \\
\text { de Investigacion } \\
\text { en Sarcomas }\end{array}$ & $\begin{array}{l}\text { Start: } \\
\text { May } 2017 \\
\text { Completion: } \\
\text { September } \\
2020\end{array}$ & NCT03275818 \\
\hline $\begin{array}{l}\text { Nab-paclitaxel in combination with } \\
\text { gemcitabine for pediatric relapsed } \\
\text { and refractory solid tumors. }\end{array}$ & 1 & Recruiting & $\begin{array}{l}\text { Dediatric relapsed and } \\
\text { refractory solid tumors }\end{array}$ & 24 & $\begin{array}{l}\text { Emory University, } \\
\text { Celgene } \\
\text { Corporation }\end{array}$ & $\begin{array}{l}\text { Start: August } \\
2018 \\
\text { Completion: } \\
\text { May } 2022\end{array}$ & NCT03507491 \\
\hline
\end{tabular}

Abbreviations: nab-paclitaxel Albumin-bound paclitaxel, STS Soft tissue sarcoma

other studies [2, 4]. The toxicity of nab-paclitaxel/ gemcitabine is also lower than that of doxorubicin and docetaxel/ gemcitabine [4]. In addition, the results of this study demonstrate that the effectiveness of nabpaclitaxel/ gemcitabine is significantly greater than that of conventional paclitaxel and docetaxel in some subtypes of STS, such as epithelioid sarcoma. Previous studies have demonstrated the limited efficacy of conventional paclitaxel and docetaxel in the treatment of epithelioid sarcoma [26, 27]. In the present study, three of the five epithelioid sarcoma patients achieved PR, and one patient achieved SD.

The results of our study indicate that nab-paclitaxel is more effective and has lower toxicity than conventional paclitaxel or docetaxel in STS. In view of the fact that nab-paclitaxel is superior to conventional paclitaxel in the treatment of many malignant tumors [13, 24, 25], nab-paclitaxel should not simply be considered as a drug with similar properties to paclitaxel. It should be regarded as a new chemotherapeutic drug; and the efficacy of this drug should be evaluated in various malignancies. For example, though paclitaxel is considered to be ineffective in the treatment of osteosarcoma [28], it should not be assumed that treatment of osteosarcoma with nab-paclitaxel is also ineffective. Indeed, we speculate that treatment of osteosarcoma with nab-paclitaxel may yield promising results.

This study provides preliminarily results demonstrating the safety and effectiveness of nab-paclitaxel/ gemcitabine in STS treatment. Although this study has some limitations, including the small sample size, retrospective design and the lack of a control group, we can still conclude that nab-paclitaxel/ gemcitabine combination chemotherapy used in STS treatment demonstrates promising effectiveness with low toxicity, and is worthy of further study. In view of the low toxicity and convenience of nab-paclitaxel, we believe that the combination of nab-paclitaxel and other anticancer drugs (chemotherapeutic drugs, TKIs, PD-1 inhibitors) in the treatment of STS may produce significant results. In elderly sarcoma patients, where effective treatment is wanting due to poor tolerance [29], nab-paclitaxel may be of significant benefit. Fortunately, several clinical trials on the efficacy of nab-paclitaxel in sarcomas are currently recruiting patients (Table 5). To further investigate the efficacy of nab-paclitaxel in STS, a randomized clinical trial will be conducting soon (ChiCTR2000030250).

\section{Conclusions}

In conclusion, nab-paclitaxel/ gemcitabine combination chemotherapy is comparatively effective in STS treatment, demonstrates low toxicity, and is worthy of further study.

\footnotetext{
Abbreviations

Nab-paclitaxel: Albumin-bound paclitaxel; STS: Metastatic soft tissue sarcoma; median-PFS: Median progression-free survival; DCR: Disease control rate; ORR: Objective response rate; AEs: Adverse events; TKIs: Receptor tyrosine kinase inhibitors; PD-1: Programmed cell death protein 1; RECIST: Response Evaluation Criteria in Solid Tumors; PD: Progressive disease; SD: Stable disease; ECOG PS: Eastern Cooperative Oncology Group performance status; UPS: Undifferentiated pleomorphic sarcoma; PNET: Primitive neuroectodermal tumor; DOX: Doxorubicin-based; PR: Partial response; CR: Complete response
} 


\section{Acknowledgements}

We thank all Chinese patients and investigators who participated in this study.

\section{Authors' contributions}

$Z T, F Z, P L, J W, J Y, P Z, W Y$ and XW performed patient recruitment and clinical investigation. ZT conceived of the study, participated in its design and coordination and helped draft the manuscript. All authors read and approved the final manuscript.

\section{Funding}

Not applicable.

\section{Availability of data and materials}

The datasets used and/or analysed during the current study are available from the corresponding author on reasonable request.

\section{Ethics approval and consent to participate}

This study was approved by the Institutional Review Board of The Affiliated Cancer Hospital of Zhengzhou University, and was conducted in accordance with the Declaration of Helsinki. All patients provided written informed consent.

\section{Consent for publication}

Not applicable.

\section{Competing interests}

The authors declare they have no competing interests.

\section{Author details}

'Department of Bone and Soft Tissue, the Affiliated Cancer Hospital of Zhengzhou University and Henan Cancer Hospital, Zhengzhou 450008, Henan Province, China. ${ }^{2}$ Department of Medical Oncology, the Affiliated Cancer Hospital of Zhengzhou University and Henan Cancer Hospital, Zhengzhou 450008, Henan Province, China.

Received: 8 April 2020 Accepted: 21 July 2020

Published online: 28 July 2020

\section{References}

1. Yang Z, Zheng R, Zhang S, Zeng H, Li H, Chen W. Incidence, distribution of histological subtypes and primary sites of soft tissue sarcoma in China. Cancer Biol Med. 2019;16(3):565-74.

2. Judson I, Verweij J, Gelderblom H, Hartmann JT, Schöffski P, Blay J-Y, et al. Doxorubicin alone versus intensified doxorubicin plus ifosfamide for firstline treatment of advanced or metastatic soft-tissue sarcoma: a randomised controlled phase 3 trial. Lancet Oncol. 2014;15(4):415-23.

3. Tap WD, Jones RL, Van Tine BA, Chmielowski B, Elias AD, Adkins D, et al. Olaratumab and doxorubicin versus doxorubicin alone for treatment of softtissue sarcoma: an open-label phase $1 \mathrm{~b}$ and randomised phase 2 trial. Lancet. 2016;388(10043):488-97.

4. Beatrice Seddon SJS, Whelan J, Leahy M, Woll PJ, Cowie F, Rothermundt C, et al. Gemcitabine and docetaxel versus doxorubicin as first-line treatment in previously untreated advanced unresectable or metastatic soft-tissue sarcomas (GeDDis): a randomised controlled phase 3 trial. Lancet Oncol. 2017;18(10):1397-410.

5. Maki RG, Wathen JK, Patel SR, Priebat DA, Okuno SH, Samuels B, et al. Randomized phase II study of gemcitabine and docetaxel compared with gemcitabine alone in patients with metastatic soft tissue sarcomas: results of sarcoma alliance for research through collaboration study 002 [corrected]. J Clin Oncol. 2007;25(19):2755-63.

6. Wilding CP, Elms ML, Judson I, Tan AC, Jones RL, Huang PH. The landscape of tyrosine kinase inhibitors in sarcomas: looking beyond pazopanib. Expert Rev Anticancer Ther. 2019;19(11):971-91.

7. Tawbi HA, Burgess M, Bolejack V, Tine BAV, Schuetze SM. Pembrolizumab in advanced soft-tissue sarcoma and bone sarcoma (SARC028): a multicentre, two-cohort, single-arm, open-label, phase 2 trial. Lancet Oncol. 2017;18(11): 1493-501.

8. Meyer M, Seetharam M. First-line therapy for metastatic soft tissue sarcoma. Curr Treat Options in Oncol. 2019;20(1):6.
9. Fu Q, Sun J, Zhang W, Sui X, Yan Z, He Z. Nanoparticle albumin-bound (NAB) technology is a promising method for anti-cancer drug delivery. Recent Pat Anticancer Drug Discov. 2009;4(3):262-72.

10. Kundranda MN, Niu J. Albumin-bound paclitaxel in solid tumors: clinical development and future directions. Drug Des Devel Ther. 2015;9:3767-77.

11. Kudlowitz D, Muggia F. Nanoparticle albumin-bound paclitaxel (nabpaclitaxel): extending its indications. Expert Opin Drug Saf. 2014;13(6):681-5.

12. United States Food and Drug Administration. FDA approves atezolizumab for PD-L1 positive unresectable locally advanced or metastatic triplenegative breast cancer. 2019. Available from: https://www.fda.gov/drugs/ drug-approvals-and-databases/fda-approves-atezolizumab-pd-I1-positiveunresectable-locally-advanced-or-metastatic-triple-negative.

13. Ishikawa M, Iwasa $\mathrm{S}$, Nagashima K, Aoki M, Imazeki H, Hirano H, et al. Retrospective comparison of nab-paclitaxel plus ramucirumab and paclitaxel plus ramucirumab as second-line treatment for advanced gastric cancer focusing on peritoneal metastasis. Investig New Drugs. 2020;38(2):533-40.

14. Sahai V, Catalano PJ, Zalupski MM, Lubner SJ, Menge MR, Nimeiri HS, et al. Nab-paclitaxel and gemcitabine as first-line treatment of advanced or metastatic Cholangiocarcinoma: a phase 2 clinical trial. JAMA Oncol. 2018. 4(12):1707-12.

15. Higuchi T, Kawaguchi K, Miyake K, Oshiro H, Zhang Z, Razmjooei S, et al. The combination of gemcitabine and nab-paclitaxel as a novel effective treatment strategy for undifferentiated soft-tissue sarcoma in a patientderived orthotopic xenograft (PDOX) nude-mouse model. Biomed Pharmacother. 2019;111:835-40.

16. Hara N, Fujimoto $N$, Miyamoto $Y$, Yamagishi $T$, Asano M, Fuchimoto $Y$, et al. Angiosarcoma of the thoracic wall responded well to nanoparticle albuminbound paclitaxel: a case report. Drug Discov Ther. 2016;10(2):114-6.

17. Metts JL, Alazraki AL, Clark D, Amankwah EK, Wasilewski-Masker KJ, George BA, et al. Gemcitabine/nab-paclitaxel for pediatric relapsed/refractory sarcomas. Pediatr Blood Cancer. 2018;65(9):e27246.

18. Louage B, De Wever O, Hennink WE, De Geest BG. Developments and future clinical outlook of taxane nanomedicines. J Control Release. 2017; 253:137-52

19. Nagar SP, Mytelka DS, Candrilli SD, D'Yachkova Y, Lorenzo M, Kasper B, et al Treatment patterns and survival among adult patients with advanced soft tissue sarcoma: a retrospective medical record review in the United Kingdom, Spain, Germany, and France. Sarcoma. 2018;2018:5467057.

20. Nehate C, Jain S, Saneja A, Khare V, Alam N, Dubey RD, et al. Paclitaxel formulations: challenges and novel delivery options. Curr Drug Deliv. 2014 11(6):666-86.

21. Alqahtani FY, Aleanizy FS, El Tahir E, Alkahtani HM, AlQuadeib BT. Paclitaxel. Profiles Drug Subst Excip Relat Methodol. 2019;44:205-38.

22. Yared JA, Tkaczuk KH. Update on taxane development: new analogs and new formulations. Drug Des Devel Ther. 2012;6:371-84.

23. Cecco S, Aliberti M, Baldo P, Giacomin E, Leone R. Safety and efficacy evaluation of albumin-bound paclitaxel. Expert Opin Drug Saf. 2014; 13(4):511-20.

24. Lee H, Park S, Kang JE, Lee HM, Kim SA, Rhie SJ. Efficacy and safety of nanoparticle-albumin-bound paclitaxel compared with solvent-based taxanes for metastatic breast cancer: a meta-analysis. Sci Rep. 2020;10(1):530.

25. Tan H, Hu J, Liu S. Efficacy and safety of nanoparticle albumin-bound paclitaxel in non-small cell lung cancer: a systematic review and metaanalysis. Artif Cells Nanomed Biotechnol. 2019;47(1):268-77.

26. Frezza AM, Jones RL, Lo Vullo S, Asano N, Lucibello F, Ben-Ami E, et al. Anthracycline, gemcitabine, and Pazopanib in Epithelioid sarcoma: a multiinstitutional case series. JAMA Oncol. 2018;4(9):e180219.

27. Pink D, Richter S, Gerdes S, Andreou D, Tunn PU, Busemann C, et al. Gemcitabine and docetaxel for epithelioid sarcoma: results from a retrospective, multi-institutional analysis. Oncology. 2014;87(2):95-103.

28. Patel SR, Papadopoulos NE, Plager C, Linke KA, Moseley SH, Spirindonidis $\mathrm{CH}$, et al. Phase II study of paclitaxel in patients with previously treated osteosarcoma and its variants. Cancer. 1996;78(4):741-4.

29. Jones RL. Sarcomas and old age: few options for such a large patient population. Future Oncol. 2019:15(26s):11-5.

\section{Publisher's Note}

Springer Nature remains neutral with regard to jurisdictional claims in published maps and institutional affiliations. 